\title{
Editorial
}

\section{Risk assessment of hazardous substances revisited}

It is needless for occupational health doctors and scientists to mention about the importance of risk assessment of hazardous substances used in workplaces. Since the US Supreme Court sentenced the "benzene verdict" requiring better ground for the occupational exposure limit (OEL) for benzene in 1980, the research and scientific knowledge on risk assessment for hazardous substances have been greatly advanced, and the concept of risk for hazardous substances used in workplaces has been introduced into the field of occupational health. Since then, many hazardous substances have been reevaluated for effects on worker health in light of the risk assessment approach. In particular, the occupational health standards for occupational carcinogens are noteworthy. The Japan Society for Occupational Health (JSOH) recommends the reference values of $1 \mathrm{ppm}$ and $0.1 \mathrm{ppm}$ for benzene, corresponding to individual excess lifetime risks of cancer of $1 \times 10^{-3}$ and $1 \times 10^{-4}$, respectively, on the basis of the average relative risk model, instead of the conventional OEL value. The JSOH also recommends the reference values for other occupational carcinogens including arsenic and its compounds (as As), asbestos and nickel smelting dusts (as Ni) as well as ionizing radiation. A characteristic feature of these carcinogenic reference values is that they are expressed as occupational standard concentrations with an excess lifetime cancer risk level of $1 / 1,000$ or $1 / 10,000$. It was thus suggested that there is no threshold level for induction of cancer in comparison with noncarcinogenic compounds having a threshold level below which there is no risk of any adverse health effect.

Recently in Japan, we had two tragic incidents that raised serious concerns regarding the health of workers handling two hazardous substances, i.e., indium and 1,2-dichloropropane (DCP). The first was 10 cases of lung diseases attributable to occupational exposure to indium and its compounds reported in Japan as of 2010, including 7 cases of interstitial pneumonia. In 2010, the Japan Ministry of Health, Labour and Welfare (MHLW) issued a Technical Guideline for Preventing Health Impairment of Workers Engaged in the Indium-Tin Oxides Handling Processes. In order to protect workers from excessive exposure to indium and its compounds in workplaces, employers are required to implement actions and measures by assessing workplace air concentrations of indium-containing respirable dust, using two occupational standards. The MHLW established the two standards: a target concentration of indium in respirable dust of $0.01 \mathrm{mg} \mathrm{In} / \mathrm{m}^{3}$ and an acceptable exposure limit of indium of $0.0003 \mathrm{mg} \mathrm{In} / \mathrm{m}^{3}$. The latter value was derived on the basis of the quantitative carcinogenic risk assessment approach, using the dose-response data obtained from an 104-wk carcinogenic and chronic toxicity study showing a significant increase in the incidence of lung cancer in rats in close association with various pathological changes including chronic fibrosis in the lung of rats and mice ${ }^{1)}$. The second incident involved male offset color proof-printing workers at a small company in Osaka, who were exposed to high levels of DCP and dichloromethane vapor, and diagnosed with cholangiocarcinoma ${ }^{2}$. Several printing workers died of bile duct cancer. The MHLW revised the administrative control level (ACL) of DCP from $10 \mathrm{ppm}$ to $1 \mathrm{ppm}$, designating this substance as a possible occupational carcinogen in accordance with the Industrial Safety and Health (ISH) Act. The JSOH also recommended an OEL value of $1 \mathrm{ppm}$ for 1,2-dichloropropane, classifying this substance as Group 1 (confirmed human carcinogen with epidemiological evidence).

In view of the astonishing occurrence of these two incidents of fatal occupational diseases in the first decade of the 21 st century in Japan, more comprehensive countermeasures to cope with these difficult situations were urgently needed for regulation of hazardous substances, in particular carcinogenic substances. In 2014, the National Diet of Japan passed the amended ISH Act, and the MHLW amended the ISH-related laws and regulations such as the Ordinance on Prevention of Hazards due to Specified Chemical Substances (OPHSC) and the Ordinance on Prevention of Organic Solvent Poisoning. These two ordinances were amended to implement more strict regulatory control of carcinogenic substances used in workplaces. These substances are chloroform, carbon tetrachloride, 1,4-dioxane, 1,2-dichloroethane, 
dichloromethane, styrene, 1,1,2,2-tetrachloroethane, tetrachloroethylene, trichloroethylene, methyl isobutyl ketone, ethylbenzene, and 1,2-dichloropropane, all of which are classified as carcinogens of Groups 1 (human carcinogen with epidemiological evidence), 2A (probable human carcinogen), or 2B (possible human carcinogen) by the International Agency for Research on Cancer (IARC). For instance, the OPHSC stipulates that workers handling these substances or mixtures having $1 \%$ or more of them in workplaces must have a medical examination once every 6 months, and that the workplace air concentrations of these substances must be measured once every 6 months in accordance with the analytical methods designated by the Working Environment Measurement Act. Importantly, the data from both the medical examination and work environmental measurements must be preserved for 30 years, since these substances are known to induce occupational cancer after a long latency period. The ISHrelated ordinance designates 37 substances including the abovementioned 12 organic solvents as the carcinogens termed as "special control substances". It is, however, thought that the number of occupational carcinogens regulated by the ISH-related laws is too small as compared with those that are not regulated by the laws. In contrast, the JSOH recommends a total of 176 substances as occupational carcinogens of Groups 1 (confirmed human carcinogen), 2A (probable human carcinogen), and $2 \mathrm{~B}$ (possible human carcinogen). The US National Institute for Occupational Safety and Health (NIOSH) recommends 132 substances as occupational carcinogens. Additionally, the American Conference of Governmental Industrial Hygienists (ACGIH) recommends 139 substances as carcinogens classified as A1 (confirmed human carcinogen), A2 (suspected human carcinogen), and A3 (confirmed animal carcinogen with unknown relevance to humans). The recent amendment of the OPHSC seems to be an important step toward reduction of occupational cancers. However, we have to cope with many other carcinogenic substances used in workplaces that are not regulated by the ISH-related laws and regulations. Now, employers are effectively required to take initiative to control many other occupational carcinogens that are not regulated by the ISH-related laws. At present, we have to rely on a lot of information about carcinogenicity of hazardous substances coming from the USA and Europe.

Another feature of the recent OPHSC amendment is that employers are obligated to assess health risks of hazardous substances used in workplaces in light of an appro- priate risk assessment approach. For instance, employers must provide information about safety and health effects of hazardous substances and methods of handling these substances in the form of a Safety Data Sheet (SDS) in accordance with the global harmonization standard (GHS). When these hazardous substances are used and handled in workplaces, employers must provide the SDSs for the substances listed in the OPHSC. There are a total of 640 substance that the OHPSC asks employers to provide SDS for, not only for the transaction of materials from suppliers to recipients but also for appropriate control of work environment, in order to protect workers from occupational diseases resulting from excessive exposure to these substances. Many occupational carcinogens are included in the list of 640 substances. The ACGIH recommends OEL values for these 640 substances. The NIOSH establishes the Recommended Exposure Limits (RELs) for 586 substances. In Germany, MAK values (maximum workplace concentrations) have been recommended for 340 hazardous substances without carcinogenicity in addition to 163 occupational carcinogens classified as Categories 1 (human carcinogens) and 2 (probable human carcinogens). On the other hand, the JSOH recommends OELs for 220 substances. The MHLW established ACLs only for 91 substances. The differences in the number of hazardous substances recommended or regulated by laws between Japan and the USA or Europe suggest that we rely on a lot of information about various health effects coming from the USA and Europe, and that much more efforts should be made by employers of Japanese enterprises to cope effectively with the requirements imposed by the recently amended ISH-related law and regulations. As it was for the "benzene verdict" 35 years ago in the USA, it is now time in Japan for the agenda concerning risk assessment of hazardous substances to be revisited. In order to fulfill the regulatory requirements imposed by the recently amended OPHSC and to cope adequately with the present circumstances, employers of Japanese enterprises, government, and academia have to study together and work together. Effective cooperation among these three stakeholders will promote worker health and prevention of occupational diseases through appropriate implementation of risk assessment for many hazardous substances used in workplaces.

\section{References}

1) Nagano K, Nishizawa T, Umeda $Y$, Kasai $T$, Noguchi $T$, Gotoh K, Ikawa N, Eitaki Y, Kawasumi Y, Yamauchi T, 
Arito H, Fukushima S (2011) Inhalation carcinogenicity and chronic toxicity of indium-tin oxide in rats and mice. $\mathrm{J}$ Occup Health 53, 175-87. [Medline] [CrossRef]

2) Kumagai S, Kurumatani N, Arimoto A, Ichihara G
(2013) Cholangiocarcinoma among offset colour proofprinting workers exposed to 1,2-dichloropropane and/ or dichloromethane. Occup Environ Med 70, 508-10. [Medline] [CrossRef]

\section{Heihachiro ARITO}

Japan Industrial Safety and Health Association, Occupational Health Research and Development Center, Japan 